\title{
Role of evaluating tumor-infiltrating lymphocytes, programmed death-1 ligand 1 and mismatch repair proteins expression in malignant mesothelioma
}

\author{
LORENA LOSI $^{1,4}$, FEDERICA BERTOLINI ${ }^{2}$, GIORGIA GUAITOLI ${ }^{2,3}$, LUCA FABBIANI $^{3,4}$, \\ FEDERICO BANCHELLI ${ }^{3}$, ANDREA AMBROSINI-SPALTRO ${ }^{4}$, LAURA BOTTICELLI ${ }^{4}$, LETIZIA SCURANI ${ }^{1}$, \\ CINZIA BALDESSARI ${ }^{2,3}$, FAUSTO BARBIERI ${ }^{2}$, STEFANO CASCINU ${ }^{2,3}$ and ANTONINO MAIORANA ${ }^{3,4}$ \\ ${ }^{1}$ Department of Life Sciences, University of Modena and Reggio Emilia; \\ ${ }^{2}$ Division of Medical Oncology, Azienda Ospedaliero-Universitaria Policlinico; \\ ${ }^{3}$ Department of Medical and Surgical Sciences for Children and Adults, University of Modena and Reggio Emilia; \\ ${ }^{4}$ Unit of Pathology, Azienda Ospedaliero-Universitaria Policlinico, I-41124 Modena, Italy
}

Received March 26, 2019; Accepted July 26, 2019

DOI: 10.3892/ijo.2019.4883

\begin{abstract}
The tumor immune microenvironment (TME) and immune checkpoints have been reported to serve a role in the pathogenesis of malignant mesothelioma (MM) and treatment outcome. Additionally, mismatch Repair (MMR) deficiency appears to enhance the response to checkpoints blockade in several tumors. The aim of the present study was to analyze programmed death-1 ligand 1 (PD-L1) expression in MM and to characterize the TME. This could help to understand the immune response, and evaluate its prognostic and predictive values. We also investigated MMR protein expression. We retrospectively analyzed 55 mesotheliomas to determine PD-L1, CD4 ${ }^{+}, \mathrm{CD}^{+}$, mutL homolog 1 (MLH1), mutS homolog 2 (MSH2), mutS homolog 6 (MSH6) and PMS1 homolog 2, mismatch repair system component (PMS2) expression. We used an immunoscore $(1+, 2+$ and $3+)$ to evaluate tumor-infiltrating lymphocytes (TILs). TILs were observed in all but two samples (53/55); the majority had an immunoscore 1+ (30/53), while $2+/ 3+$ was reported for $23 / 53$ samples. A predominance of $\mathrm{CD}^{+}$was highlighted in 8 cases (15\%). PD-L1 expression of $\geq 1 \%$ on tumor cells was displayed in 40 cases; in 9 of these, $\geq 50 \%$ expression was reported. Of note, alterations in MMR staining was not observed. In addition, survival analysis revealed that epithelioid subtype was associated with better prognosis. We observed a trend towards poorer prognosis for $\geq 50 \%$ PD-L1 expression on tumor cells, lower
\end{abstract}

Correspondence to: Professor Lorena Losi, Department of Life Sciences, University of Modena and Reggio Emilia, Largo del Pozzo 71, I-41124 Modena, Italy

E-mail: lorena.losi@unimore.it

Key words: malignant mesothelioma, tumor-infiltrating lymphocytes, programmed death-1 ligand 1 , mismatch repair, tumor immune microenvironment immunoscore (1+) and $\mathrm{CD} 8^{+} \mathrm{TIL}$ predominance. The present study highlighted the importance of exploring the TME and the standardization of PD-L1 assessment guidelines to apply in the field of immunotherapy.

\section{Introduction}

Malignant mesothelioma (MM) is an aggressive and fatal tumor, frequently related to the prolonged exposure to asbestos. Although it is a rare disease, its incidence has been increasing in recent years due to the use of asbestos for many years in the past $(1,2)$. Better survival is achieved with multimodal approaches, in particular when surgery, radiotherapy and chemotherapy (platinum compounds-pemetrexed) are used. Nevertheless, treatment has a moderate impact on survival; thus, novel therapeutic strategies are urgently required to improve prognosis, for example the use of immunotherapy (3). According to the recent pathological classification proposed by the World Health Organization, mesotheliomas can be divided into three main subtypes: Epithelioid, sarcomatoid and biphasic (4). Epithelioid MM is the most common subtype and has better prognosis, while the sarcomatoid one is the rarest type with the poorest prognosis (4). MM has been reported as an immunogenic tumor that induces infiltration of immune effector cells, regulatory $\mathrm{T}$ cells and cytokines $(5,6)$; the immunological aspects of the disease require further investigation.

Is well known that tumor immune microenvironment (TME) serves a major role in neoplastic progression, facilitating tumor cell evasion from adaptive immunity and T-cell checkpoint pathways (7). Among the factors implicated in immune response inhibition by tumor cells, programmed death-1 ligand 1 (PD-1) and its main ligand PD-L1 play a key role (7). PD-L1 acts as a negative regulator of T lymphocytes (8-10): It is expressed by T-cells, B cells, monocytes and several tumor-infiltrating lymphocytes (TILs) and it has an important role in attenuating antitumor immune response. In addition, PD-L1 expression has been widely reported in several malignant tumors (11). Cancer cells expressing PD-L1 promote 
the apoptosis of antigen-specific human T-cell clones (12) and inhibit $\mathrm{CD}^{+}$and $\mathrm{CD}^{+}$T-cell activation, thus decreasing the immune action against tumor cells (12). Immune checkpoint inhibitors (ICIs) have already shown promising results in other tumors (13), and are also under investigation in MM in which the expression of PD-L1 has been detected, regardless of the predictive value in this neoplasia $(3,14) . \geq 1 \%$ PD-L1 expression is reported with different percentages in patients with MM (15-21), with higher positivity rates in non-epithelioid subtypes $(18,19)$.

Given the interaction between immune infiltrate and neoplastic cells, the characterization of TME could be of great value not only to understand the immune response, but also to determine its possible prognostic value.

Additionally, the value of the combined immunoscore (PD-L1 expression in both tumor and immune cells) is increasing due to recent data in other tumor types (e.g. head and neck cancer). In particular the combined immunoscore seems to better predict efficacy to immunotherapy (22). Nevertheless, many studies into this field are lacking conclusive data (23).

An important role in various malignancies is played by mismatch repair (MMR) genes, such as mutL homolog 1 (MLH1), mutS homolog 2 (MSH2), mutS homolog 6 (MSH6) and PMS1 homolog 2, mismatch repair system component (PMS2). Some mismatch repair-deficient tumors are sensitive to immune check point blockade, as of the increased number of neoantigens encoded by cancers, which enhance the anti-tumor response (24-26). Several studies have shown that the number of mutations in MMR genes correlates with the response to PD-1 blockade, providing further support for a relationship between mutational burden and treatment response $(25,27)$. MMR-deficiency may be considered in the identification of patients who may benefit from PD-1 pathway blockade.

MM has a lower tumor mutational burden when compared with other cancers (28); however, some patients may benefit from ICIs; this response may be related to the presence of immune cells in tumor microenvironment.

The aim of this retrospective study was to evaluate PD-L1 expression in tumor cells and TILs in different histological subtypes of MM, and to characterize the immune microenvironment. MMR protein expression was been also investigated. Additionally, these parameters were evaluated in association with clinicopathological features to explore their possible prognostic value.

\section{Materials and methods}

Patient selection and samples. Fifty-eight consecutive cases of MM were collected from January 2014 to December 2017 at the Division of Medical Oncology of Azienda Ospedaliero-Universitaria Policlinico of Modena. Out of the initial cohort, 55 surgical formalin-fixed and paraffin embedded specimens were available from the Unit of Pathology of Modena and were histologically identified with a light microscope as MM after staining with hematoxylin and eosin. The cases included 10 samples from females and 45 from males. The median age at diagnosis was 74 years old (range 45-88 years). All the samples were obtained through surgical biopsies. The study was approved by the Ethical Committee of Azienda Ospedaliero-Universitaria of Modena (393/17).
Immunohistochemistry. All immunostainings were performed on the automated system Ventana BenchMark XT (Roche Diagnostics) (29) using the detection kit UltraView DAB; in the case of double staining for CD4 and CD8, the UltraView universal alkaline phosphatase red detection kit (Roche Diagnostics) according to the manufacturer's instructions. The following primary antibodies were used: Anti PD-L1 (clone 22C3, cat. no. M3653, Dako; Agilent Technologies, Inc.) diluted 1:100, anti-human CD4 (cat. no. 790-4423) and anti-human CD8 (cat. no. 790-4460) for TILs (Roche Diagnostics), and antibodies against MLH1 (cat. no. 790-5091), MSH2 (cat. no. 790-5093), MSH6 (cat. no. 790-5092) and PMS2 (cat. no. 790-5094) for MMR-related protein expression (Roche Diagnostics) prediluted. The use of 22C3 PD-L1 staining on Ventana's platform was supported by the assuring results reported in a recent paper (30). Positive controls were included in each staining run, human placenta for PD-L1, human tonsil for the immune markers, obtained from the Unit of Pathology of Modena. For MMR protein expression, a positive internal control was represented by non-neoplastic adjacent cells present in each slide. All sections were scored by two observers including one pathologist. PD-L1 expression was retained when tumor cells or TILs displayed a membranous staining, partial or complete of any intensity. The percentage of PD-L1 positive tumor cells relative to all viable tumor cells present in the specimen was recorded. PD-L1 positivity was defined as $\geq 1 \%$ of tumor cells or TILs staining by immunohistochemistry (31). Tissue sections were analyzed for the presence of tumor lymphocytic infiltration scored according to Marcq et al (15). Therefore, we analyzed the presence of lymphocytes and lymphoid aggregates (score $0=0$ aggregates; score $1=1-5$ aggregates; score $2=5-10$ aggregates; score $3=>10$ aggregates) (15). A lymphoid aggregate was defined as $\geq 50$ lymphocytes clustered together (15). Then, cases were classified in negative when absence of tumor lymphocytic infiltration was observed; immunoscore 1+ (score 1); immunoscore 2+ (score 2 ); immunoscore $3+$ (score 3 ). To analyze the $\mathrm{CD}^{+}$and $\mathrm{CD}^{+}$components, a percentage of expression of each marker was obtained via the evaluation of the total TILs.

Statistical analysis. Descriptive statistics of the study patients were reported. Continuous variables were expressed as mean, median, standard deviation and range, while categorical variables as absolute and percentage frequencies. Associations between categorical variables were assessed by means of Fisher exact tests. The Mann-Whitney test was performed to evaluate the relationship between PD-L1 expression and histological subtype (epithelioid vs. others), stage at diagnosis, smoking history, professional asbestos exposure and gender. Overall survival times from diagnosis were graphically reported as Kaplan-Meier survival curves which were compared using a log-rank test. The survival analysis compared PD-L1 expression using different systems: In the first analysis, PD-L1 expression evaluated on tumor cells, TILs, and on both cells types was stratified into $<1$, $1-49$ and $\geq 50 \%$. In the second analysis, PD-1 expression was stratified into $<50$ and $\geq 50 \%$, and in the third analysis into $<1$ and $\geq 1 \%$. Comparisons between survival curves were expressed as hazard ratios (HR) with $95 \%$ confidence interval from a Cox regression model. Statistical analyses 
were performed with R 3.4.3 (The R Foundation for statistical computing, Wien). $\mathrm{P}<0.05$ was considered to indicate a statistically significant difference.

\section{Results}

Patient population. Samples comprised 44 epithelioid, 3 sarcomatoid, 7 biphasic and 1 desmoplastic tumors; 51 involved the pleura and 4 the peritoneum. According to the American Joint Committee on Cancer (32), 18 tumors were of stage I, 13 of stage II, 15 of stage III and 5 of stage IV; for 4 cases, the stage could not be evaluated. None of the patients received immunotherapy. The clinicopathological features of our MM series are summarized in Table I.

Immune composition of MM tissue samples. TILs were observed in all but two samples (53/55). The majority of cases had an immunoscore $1+(30 / 53)$, while an immunoscore $2+$ or $3+$ was observed in $15 / 53$ and $8 / 53$ tissue samples, respectively. Tissue sections were stained for two immune cell markers. CD4+ and $\mathrm{CD}^{+}$TILs were present in all 53 samples. The $\mathrm{CD}^{+} / \mathrm{CD}^{+}{ }^{+}$ratio was calculated dividing the percentage of CD8 positive cells on CD4 positive cells; the predominance of $\mathrm{CD}^{+}$compared with $\mathrm{CD}^{+}{ }^{+}$was defined as a ratio $>1$. A predominance of $\mathrm{CD}^{+}$expression was highlighted in 8 cases (15\%). Representative examples of different immunoscore and $\mathrm{CD}^{+}{ }^{+}$and $\mathrm{CD}^{+}$predominance are presented in Fig. 1.

PD-L1 expression on tumor cells and TILs, and its association with tumor lymphocyte infltration. The immunohistochemical analysis for PD-L1, using a threshold of $\geq 1 \%$ of tumor cells, showed membranous expression of PD-L1 in 40 tumors (73\%) whereas 15 (27\%) were negative (Fig. 2). According to Herbst et al (31), we added a third stratification variable considering PD-L1 expression $\geq 50 \%$ of cells: Among the 40 positive cases, it was observed in 9 cases ( 5 epithelioid, 2 sarcomatoid, 1 biphasic and 1 desmoplastic). In two of them (one biphasic and one epithelioid), this high positivity was present both on tumor cells and on TILs. The expression of PD-L1 on TILs was detected in 32 cases $(60 \%)$, of which two samples exhibited $>50 \%$ of PD-L1 staining (Fig. 2). PD-L1 positivity was evaluated both on tumor cells and TILs. In 11 cases negative expression was detected in both cell types, while 28 cases were positive both on tumor cells and TILs. In 23 of these, the results were concordant with PD-L1 between 1-49\% and in two samples with PD-L1 $\geq 50 \%$; while in three cases PD-L1 $\geq 50 \%$ was found only on tumor cells (Table II). In 10 cases PD-L1 positivity was detected only on tumor cells, 7 with PD-L1 between $1-49 \%$ and 3 with $\geq 50 \%$ (Table II). On the contrary, in 4 cases, PD-L1 was positive only on TILs, yet to a low degree (1\%) (Table II).

The association between PD-L1 expression and $\mathrm{CD}^{+}$or $\mathrm{CD}^{+}$predominance was reported in Table III $(\mathrm{P}=0.058)$. A predominance of $\mathrm{CD} 4+$ infiltrate was observed in the majority of tumors independently of PD-L1 expression. The correlation of PD-L1 and immunoscore is displayed in Table III. Higher immunoscore $(2+/ 3+)$ was significantly associated to an intermediate PD-L1 expression (1-49\%) $(\mathrm{P}=0.019)$. Representative examples of PD-L1 immunostaining are shown in Fig. 1.

Table I. Clinicopathological features of mesothelioma patients.

Clinicopathological features

Age (mean $\pm \mathrm{SD}$, years)

Median (range)

Sex

Male

Female

Histological subtype

Epithelioid

Sarcomatoid

Biphasic

Desmoplastic

Smoking history

Never smoker

Current/former smoker

Unknown

Professional asbestos exposure

Yes

No

Site

Peritoneum

Pleural

Stage

I

II

III

IV

Unknown
Patients $n=55$

$73.7 \pm 8.2$

$74(43-88)$

$45(82 \%)$

$10(18 \%)$

$44(80 \%)$

$3(5 \%)$

$7(13 \%)$

$1(2 \%)$

$78(14 \%)$

$28(51 \%)$

$19(35 \%)$

$30(55 \%)$

$25(45 \%)$

$4(7 \%)$

$51(93 \%)$

$18(33 \%)$

$13(24 \%)$

$15(27 \%)$

$5(9 \%)$

$4(7 \%)$

SD, standard deviation.

MMR protein expression. In all the analyzed MM samples, no alteration in MMR staining was found.

Association between PD-L1 expression and clinicopathological features. $\geq 50 \%$ PD-L1 expression on tumor cells was significantly less common in the epithelioid subtype than in the other types $(\mathrm{P}=0.047)$. The absence of an association between PD-L1 expression was found with smoking history, asbestos exposure and stage. Furthermore, the link between gender with immune checkpoints showed no statistically significant differences. The association with PD-L1 expression on tumor cells was evaluated with three systems: $<1$ and $\geq 1 \% ;<1,1-49, \geq 50 ;<50$ and $\geq 50 \%$ $(\mathrm{P}=0.282 ; \mathrm{P}=0.572 ; \mathrm{P}=0.202)$. Also, the $\mathrm{CD}^{+} / \mathrm{CD}^{+}$ratio $(\mathrm{P}=0.097)$ and immunoscore $2+/ 3+$ vs. $1+(\mathrm{P}=0.164)$ exhibited no association with gender (data not shown).

Association of PD-L1 expression and tumor immune infiltrate with survival. After an average follow up of 14.4 months, 22 (40.0\%) patients were still alive; all but two had epithelioid mesothelioma, and the majority of them had PD-L1 expression $<50 \%$. The median overall survival time was 13.3 months. Median survival for patients for negative $(<1 \%)$, moderate 

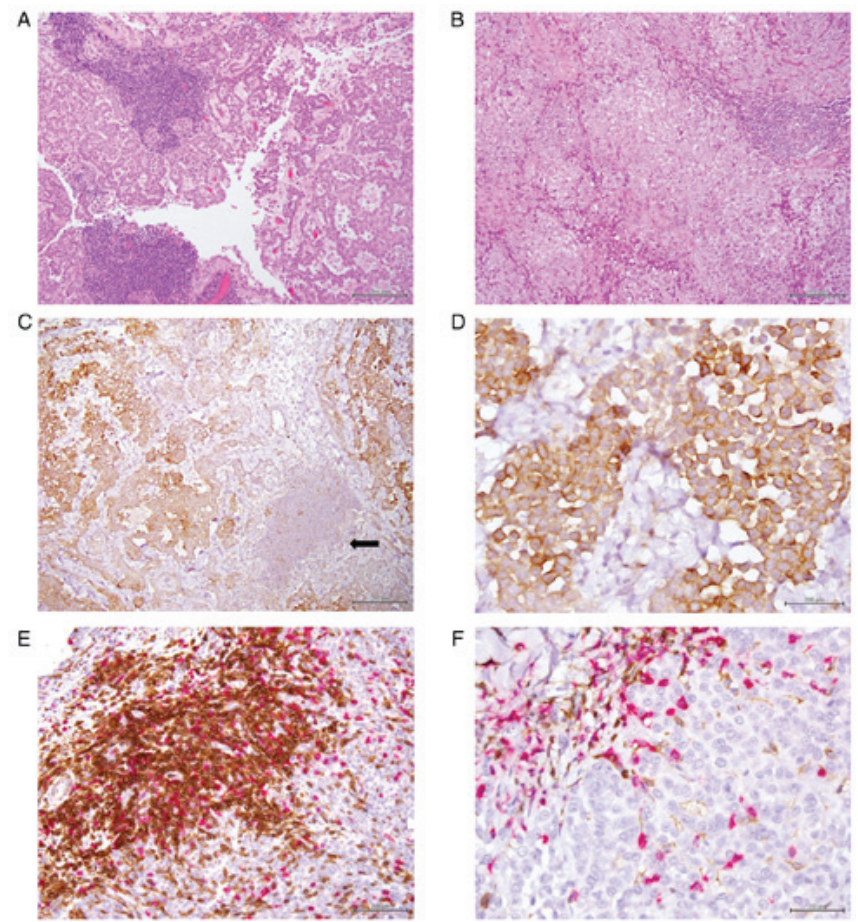

Figure 1. TILs of malignant mesothelioma tissue samples. Staining with hematoxylin and eosin indicated the presence of lymphoid aggregates. Immunoscore (A) 3+ and (B) 1+ (original magnification x100). Immunohistochemistry of PD-L1 expression on tumor cells and TILs. (C and D) Highly PD-L1-positive tumor cells $\geq 50 \%$. The arrow in panel C indicates a lower positivity for PD-L1 in TILs. Original magnifications x100 and 400 . The double immunohistochemical staining demonstrated the presence of lymphoid aggregates with $\mathrm{CD} 4^{+}$(brown) and $\mathrm{CD} 8^{+}$(red) lymphocytes (E) Predominance of $\mathrm{CD}^{+}$, original magnification x200; (F) Predominance of $\mathrm{CD}^{+}$, original magnification $\mathrm{x} 400$. TILs, tumor-infiltrating lymphocytes.

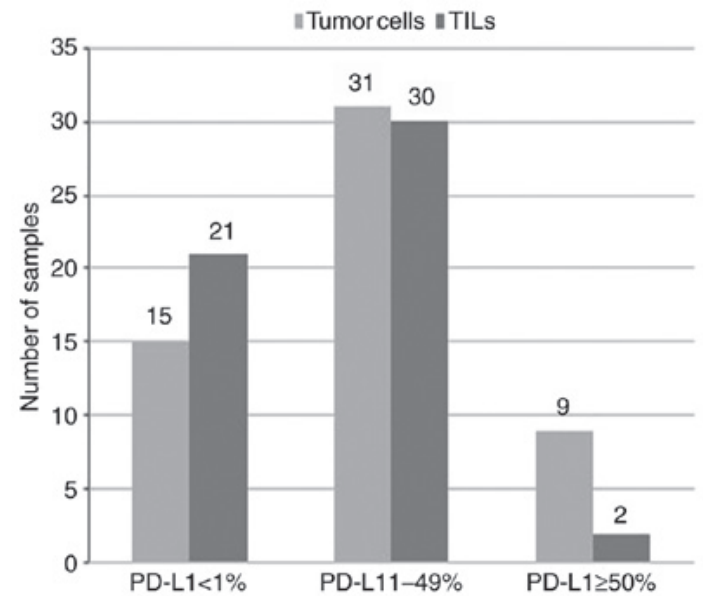

Figure 2. Histogram of the cases characterized by PD-L1 expression on tumor cells and TILs. PD-L1, programmed death-1 ligand 1; TILs, tumor-infiltrating lymphocytes.

(from $1-49 \%$ ) and strong PD-L1 staining ( $\geq 50 \%$ ) was 13.0, 20.6 and 5.1 months, respectively. Median survival for epithelioid subtype was 17.3 months, while for other subtypes it was 5.9 months. According to the $\mathrm{CD} 8^{+} / \mathrm{CD}^{+}$ratio, median survival in patients with $\mathrm{CD} 8^{+}$predominance was 3.3 months, while for $\mathrm{CD}^{+}$predominance was 17.3 months. Furthermore, patients with an immunoscore 1+ had 13.0 months of overall
Table II. Combined expression of PD-L1 on TC and TILs.

\begin{tabular}{|c|c|c|c|}
\hline \multirow[b]{2}{*}{ Cells } & \multicolumn{2}{|c|}{ PD-L1 $\geq 1 \%$} & \multirow[t]{2}{*}{ PD-L1 $<1 \%$} \\
\hline & $1-49 \%$ & $\geq 50 \%$ & \\
\hline \multirow{2}{*}{ TC and TILs } & \multicolumn{2}{|c|}{$28 / 53(54 \%)$} & $11 / 53(20 \%)$ \\
\hline & $23 / 53$ & $2 / 53 ; 3 / 53$ (TC) & \\
\hline \multirow{2}{*}{ TC only } & \multicolumn{2}{|c|}{$10 / 53(19 \%)$} & \\
\hline & $7 / 53$ & $3 / 53$ & \\
\hline TILs only & \multicolumn{2}{|c|}{$4 / 53(7 \%)$} & \\
\hline
\end{tabular}

Number of all positive samples are shown. Expression of PD-L1 using a threshold of $\geq 1 \%$ and stratified in two groups (1-49\% and $\geq 50 \%$ ) was evaluated. PD-L1, programmed death-1 ligand 1; TC, tumor cells; TILs, tumor-infiltrating lymphocytes.

median survival, whereas it was equal to 20.6 months in patients with an immunoscore $2+/ 3+$.

Survival curves based on the PD-L1 expression percentage $(<1,1-49, \geq 50 \%)$, histological subtype, $\mathrm{CD} 4^{+}$or $\mathrm{CD} 8^{+}$ predominance (expressed as $\mathrm{CD} 8^{+} / \mathrm{CD}^{+}$ratio; Table IV) and immunoscore (2+/3+ vs. 1+) are presented in Fig. 3 and HR values are listed in Table IV. Additionally, survival curves based on PD-L1 expression on tumor cells $(<1$ and $\geq 1 \%)$ exhibited no statistically significant differences (Fig. S1).

Epithelioid subtype was associated with lower risk of death during the follow-up period ( $\mathrm{HR}=0.4295 \% \mathrm{CI}=0.19-0.92$; $\mathrm{P}=0.031$ ). Moreover, we observed a trend toward a poorer prognosis for PD-L1 expression on tumor cells $\geq 50 \%$, lower immunoscore (1+) and $\mathrm{CD}^{+}$tumor-infiltrating lymphocytes predominance. When we consider only two groups of PD-L1 expression $(<50$ and $\geq 50 \%)$, the association with survival was more apparent; however, statistical significance was not observed $(\mathrm{P}=0.116)$. Furthermore, the association between PD-L1 expression on TILs ( $\mathrm{P}=0.906$ for $<1,1-49$ and $\geq 50 \%$; $\mathrm{P}=0.657$ for $<1$ and $\geq 1 \%$ ) and the combined expression on tumor cells and TILs $(\mathrm{P}=0.285)$ with survival were not statistically significant.

As the extent of PD-L1 positivity was less observed in the epithelioid subtype, we applied the survival analysis only on these cases. Under these conditions, no statistically significant association was reported between PD-L1 expression and survival $(\mathrm{P}=0.362$ for $<1,1-49$ and $\geq 50 \%$; $\mathrm{P}=0.974$ for $<1$ and $\geq 1 \%$; $\mathrm{P}=0.168$ for $<50$ and $\geq 50 \%$ ). Additionally, $\mathrm{CD}^{+} / \mathrm{CD} 4^{+}$ratio $(\mathrm{P}=0.474)$ and immunoscore $2+/ 3+$ vs. $1+$ $(\mathrm{P}=0.183)$ were not linked to survival.

\section{Discussion}

The present study aimed to evaluate PD-L1 expression on tumor cells and on TILs, to characterize the immune microenvironment and investigate MMR protein expression in MM. We also explored the possible prognostic value of these parameters.

In our series of MM, PD-L1 expression on tumor cells was observed in $73 \%$ of cases using a cut-off value of $\geq 1 \%$. This finding is in accordance with several studies $(13,16,17)$, 
Table III. Association between of PD-L1 expression on tumor cells and $\mathrm{CD} 4^{+}$or $\mathrm{CD}^{+}$predominance and immunoscore

\begin{tabular}{|c|c|c|c|c|c|c|c|}
\hline \multirow{3}{*}{$\begin{array}{l}\text { PD-L1 expression } \\
\text { on tumor cells }\end{array}$} & \multirow{3}{*}{$\begin{array}{l}\text { Number of } \\
\text { samples }^{\mathrm{a}}\end{array}$} & \multicolumn{2}{|c|}{$\mathrm{CD}^{+} / \mathrm{CD}^{+}$} & \multirow[b]{3}{*}{ P-value } & \multirow{2}{*}{\multicolumn{2}{|c|}{ Immunoscore }} & \multirow[b]{3}{*}{ P-value } \\
\hline & & \multirow{2}{*}{$\begin{array}{l}\text { Predominance } \\
\text { of } \mathrm{CD}^{+}(\%)\end{array}$} & \multirow{2}{*}{$\begin{array}{c}\text { Predominance } \\
\text { of } \mathrm{CD}^{+}(\%)\end{array}$} & & & & \\
\hline & & & & & $1+(\%)$ & $2+/ 3+(\%)$ & \\
\hline$\geq 50 \%$ & 8 & $3(37.5)$ & $5(62.5)$ & $\mathrm{P}=0.058^{\mathrm{b}}$ & $5(62.5)$ & $3(37.5)$ & $\mathrm{P}=0.019^{\mathrm{b}}$ \\
\hline $1-49 \%$ & 31 & $2(6.5)$ & $29(93.5)$ & & $13(41.9)$ & $18(58.1)$ & \\
\hline$<1 \%$ & 14 & $3(21.4)$ & $11(78.6)$ & & $12(85.7)$ & $2(14.3)$ & \\
\hline Total & 53 & $8(15.1)$ & 45 (84.9) & & $30(56.7)$ & $23(43.3)$ & \\
\hline
\end{tabular}

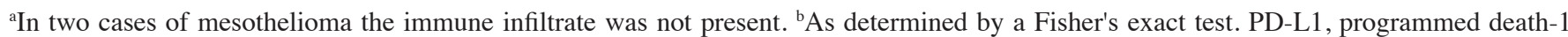
ligand.

Table IV. Univariate analysis of pathological variables on overall survival.

Univariate Cox analysis

\begin{tabular}{|c|c|c|c|}
\hline \multirow[b]{2}{*}{ Variables } & \\
\hline & HR & $95 \mathrm{CI} \%$ & P-value \\
\hline \multicolumn{4}{|c|}{ PD-L1 expression on tumor cells } \\
\hline$\geq 50$ vs. $<1 \%$ & 1.58 & $0.57-4.39$ & 0.376 \\
\hline $1-49$ vs. $<1 \%$ & 0.70 & $0.32-1.53$ & 0.367 \\
\hline \multicolumn{4}{|l|}{ Histological subtype } \\
\hline Epithelioid vs. Other & 0.42 & $0.19-0.92$ & $0.19-0.92$ \\
\hline \multicolumn{4}{|l|}{$\mathrm{CD}^{+} / \mathrm{CD}^{+}{ }^{+}$Ratio } \\
\hline$\geq 1$ vs. $<1$ & 1.96 & $0.68-5.67$ & 0.215 \\
\hline \multicolumn{4}{|l|}{ Immunoscore } \\
\hline $2+/ 3+$ vs. $1+$ & 0.76 & $0.37-1.60$ & 0.476 \\
\hline
\end{tabular}

CI, confidence interval; HR, hazard ratio; PD-L1, programmed death-1 ligand.

which reported percentage from 54-68\%, but differs from others (18-21), which revealed a lower percentage of positivity (from 20.7-41.8\%). This is may be due to differences in sample size, antibodies and cut-off values, as well as patient heterogeneity among different studies. Of note, we reported an association between PD-L1 positivity and histotype. Furthermore, some studies have found lower PD-L1 expression in epithelioid subtype compared with other subtypes (15-18). PD-L1 on tumor cells was not always expressed simultaneously with PD-L1 on TILs as already reported $(15,16,21)$ and in concordance with the findings in other tumor types (33).

PD-L1 expression has been correlated with worse prognosis but better response to anti-PD-1 antibodies in many cancer types, such as NSCLC (34-37). In MM, several studies have demonstrated that PD-L1 tumor cells expression was an independent factor for worse overall survival (16,18-21). Our results showed that PD-L1 expression does not appear to be significantly associated with survival despite a trend toward a poorer prognosis with PD-L1 expression in $\geq 50 \%$ on tumor cells. The absence of a significant association with survival is in agreement with two recent studies, in which a specific antibody (SP142) (38) and four different antibodies were employed (17). This finding was observed even when we compared survival with PD-L1 expression on TILs, and with the combined expression of tumor cells and TILs. Therefore, the value of PD-L1 requires further investigation and standardization of its assessment is needed to improve clinical practice.

The predictive value of immunohistochemical screening concerning the response to anti-PD-L1 treatment for MM needs to be studied. Moreover, clinical practice may demand access to different PD-L1 antibodies matched with specific staining platforms and score criteria are required to apply a novel diagnostic tool. In addition, PD-L1 expression is a heterogeneous continuum in tumor cells that cannot be stated only as 'present' or 'absent'. The identification of a cut-off value for expression positivity based on immunohistochemistry remains a challenge at present. Also, the location of PD-L1 expression should be considered; it is presumed that membranous expression of PD-L1 may be the most relevant as PD-1 mediates downstream signaling cascades only when it has been ligated (39). Pathologists, oncologists and scientists should work together in order to develop guidelines to apply in this new field of cancer treatment.

The role of the tumor immune microenvironment in neoplastic progression is supported by a large body of evidence (40). In our series of MM, we found in less than half of cases (23/53), a higher degree of lymphocytic infiltration (expressed as immunoscore $2+/ 3+$ ) which was significantly associated to an intermediate level of PD-L1 expression. In the majority of cases $(85 \%)$, immune cell infiltration was characterized by $\mathrm{CD} 4^{+}$predominance independently of PD-L1 expression, while a predominance of $\mathrm{CD}^{+}$was detected only in $15 \%$ of mesotheliomas. Our data showed a trend toward a poorer prognosis with lower immunoscore (1+) and CD8+ TIL predominance. These findings are in line with recent literature data: CD4+ TILs are associated with better prognosis; MM cases characterized by higher CD8+ T lymphocyte expression and a lower CD4/CD8-positive ratio achieve worse survival $(13,16,20)$. In contrast, a favorable prognostic value of high levels of TILs in several tumors have been reported (41-43) and also in MM $(44,45)$. However, as their true biological role in suppressing and promoting tumor growth is governed by a variety of positive and negative T-cell factors, as well as the PD/PD-L1 pathway, further investigation is needed. 

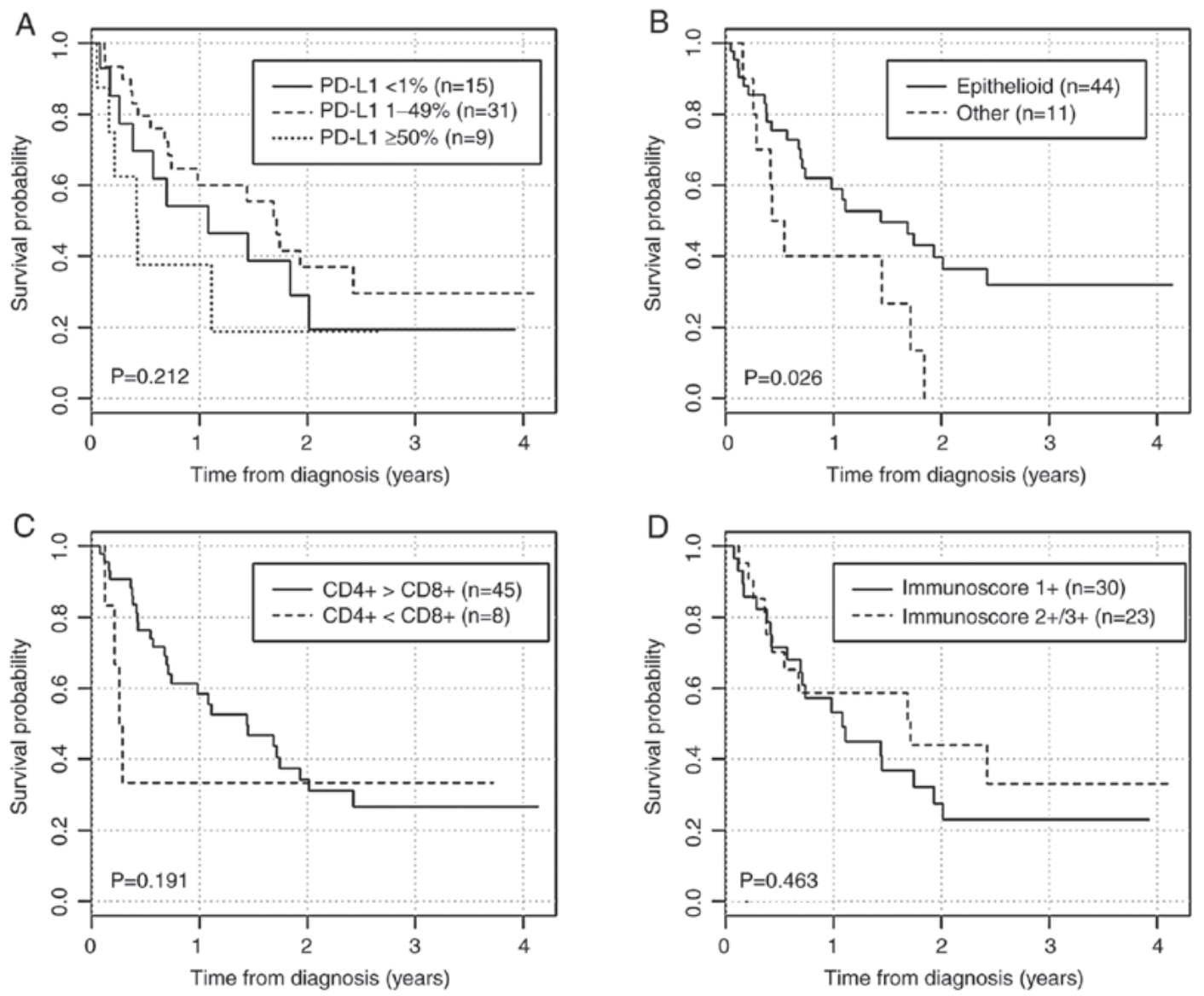

Figure 3. Kaplan-Meier survival curves. Analysis was conducted bases on (A) PD-L1 expression; (B) histological subtypes; (C) CD4 ${ }^{+}$and CD8 ${ }^{+} \mathrm{T}$ lymphocytes predominance, and (D) immunoscore (1+ vs. 2+/3+). PD-L1, programmed death-1 ligand 1.

The role of MMR in the neoplastic process is well established for several tumors (24). MMR-deficiency might be taken into consideration in order to identify those patients who may benefit from PD-1 pathway blockade. Some studies have reported a contradictory relationship between mutational burden and treatment response $(25,27)$, but further study is required. A recent report examined this in MM (46), and revealed a very low frequency (1.8\%) of MMR deficiency. In our study, none of the examined MM samples presented loss of expression of the proteins codified by the four genes $(M L H 1$, MSH2, MSH6 and PMS2). Taken together, these data suggest that the MMR pathway is less involved in the pathogenesis of mesothelioma. Other mechanisms should be investigated to understand the response to ICI.

In conclusion, in our series of $55 \mathrm{MM}$ samples, we reported that the epithelioid subtype is an independent factor of better prognosis as previously reported in the literature. The other immunological parameters, including PD-L1, immunoscore and predominance of $\mathrm{CD} 8^{+} \mathrm{TIL}$, were not significantly associated with survival, although we observed a trend toward a poorer prognosis for increased PD-L1 expression on tumor cells, lower immunoscore (1+) and CD8 $8^{+}$TIL predominance. However, we highlight the importance of the tumor immune microenvironment and the standardization of immunohistochemical techniques for PD-L1 assessment in order to obtain comparable results to improve understanding of the pathogenesis of this very aggressive neoplasia.
We reported a case series in which the immunological parameters analyzed may provide insight into the prognostic aspects of the disease. Investigation should also be conducted in a clinical setting with patients receiving immunotherapy to validate the predictive value of these parameters. Firstly, it would be important for pathologists and oncologists to work together to develop homogeneous guidelines for this new field of cancer treatment.

\section{Acknowledgements}

Not applicable.

\section{Funding}

No funding was received.

\section{Availability of data and materials}

All data generated or analyzed during this study are included in this published article.

\section{Authors' contributions}

LL and AM contributed to the conception of the study. FBer, GG, CB, FBar, SC obtained the clinical data. LL and GG wrote the manuscript and analyzed the data. FBan 
performed statistical analysis. LF performed immunohistochemical analysis. LB and AA obtained histological samples. LL, AA and LS interpreted the immunohistochemical results. All authors read and approved the final version of the manuscript.

\section{Ethical approval and consent to participate}

This study was approved by the Ethical Committee of the Azienda Ospedaliero-Universitaria of Modena (393/17).

\section{Patient consent for publication}

Not applicable.

\section{Competing interests}

The authors declare that they have no competing interests.

\section{References}

1. Merlo DF, Bruzzone M, Bruzzi P, Garrone E, Puntoni R, Maiorana L and Ceppi M: Mortality among workers exposed to asbestos at the shipyard of Genoa, Italy: A 55 years follow-up. Environ Health 17: 94, 2018.

2. Ferrante D, Chellini E, Merler E, Pavone V, Silvestri S, Miligi L, Gorini G, Bressan V, Girardi P, Ancona L, et al: Italian pool of asbestos workers cohorts: Mortality trends of asbestos-related neoplasms after long time since first exposure. Occup Environ Med 74: 887-898, 2017.

3. Alley EW, Lopez J, Santoro A, Morosky A, Saraf S, Piperdi B and van Brummelen E: Clinical safety and activity of pembrolizumab in patients with malignant pleural mesothelioma (KEYNOTE-028): Preliminary results from a non-randomised, open-label, phase $1 \mathrm{~b}$ trial. Lancet Oncol 18: 623-630, 2017.

4. Travis WD, Brambilla E, Burke AP, Marx A and Nicholson AG: WHO classification of tumours of the Lung, Pleura, Thymus and Heart. In: WHO Press. WHO Classification of Tumors, Volume 7. 4th edition. Lyon, France, 2015.

5. Hegmans JP, Hemmes A, Hammad H, Boon L, Hoogsteden HC and Lambrecht BN: Mesothelioma environment comprises cytokines and T-regulatory cells that suppress immune responses. Eur Respir J 27: 1086-1095, 2006.

6. Anraku M, Cunningham KS, Yun Z, Tsao MS, Zhang L, Keshavjee S, Johnston MR and de Perrot M: Impact of tumor-infiltrating $\mathrm{T}$ cells on survival in patients with malignant pleural mesothelioma. J Thorac Cardiovasc Surg 135: 823-829, 2008.

7. Chen DS and Mellman I: Oncology meets immunology: The cancer-immunity cycle. Immunity 39: 1-10, 2013.

8. Freeman GJ, Long AJ, Iwai Y, Bourque K, Chernova T, Nishimura H, Fitz LJ, Malenkovich N, Okazaki T, Byrne MC, et al: Engagement of the PD-1 immunoinhibitory receptor by a novel $\mathrm{B} 7$ family member leads to negative regulation of lymphocyte activation. J Exp Med 192: 1027-1034, 2000.

9. Keir ME, Francisco LM and Sharpe AH: PD-1 and its ligands in T-cell immunity. Curr Opin Immunol 19: 309-314, 2007.

10. Francisco LM, Salinas VH, Brown KE, Vanguri VK, Freeman GJ, Kuchroo VK and Sharpe AH: PD-L1 regulates the development, maintenance, and function of induced regulatory T cells. J Exp Med 206: 3015-3029, 2009.

11. Teng F, Meng X, Kong L and Yu J: Progress and challenges of predictive biomarkers of anti PD-1/PD-L1 immunotherapy: A systematic review. Cancer Lett 414: 166-173, 2018.

12. Dong H, Strome SE, Salomao DR, Tamura H, Hirano F, Files DB, Roche PC, Lu J, Zhu G, Tamada K, et al: Tumor-associated B7-H1 promotes T-cell apoptosis: A potential mechanism of immune evasion. Nat Med 8: 793-800, 2002

13. Marcq E, Pauwels P, Van Meerbeeck JP and Smits EL: Targeting immune checkpoints: New opportunity for mesothelioma treatment? Cancer Treat Rev 41: 914-924, 2015.
14. Hassan R, Thomas A, Patel MR, Nemunaitis JJ, Bennouna J, Powderly JD, Taylor MH, Dowlati A, Chen F, Leach J, et al: Avelumab (MSB0010718C; anti-PD-L1) in patients with advanced unresectable mesothelioma from the JAVELIN solid tumor phase Ib trial: Safety, clinical activity, and PD-L1 expression. J Clin Oncol 34 (15 Suppl): S8503-S8503, 2016.

15. Marcq E, Siozopoulou V, de Waele J, van Audenaerde J, Zwaenepoel K, Santemans E, Heins N, Pauwels P, van Meerbeeck JP and Smits EL: Prognostic and predictive aspects of the tumor immune microenvironment and immune checkpoints in malignant pleural mesothelioma. Oncoimmunology 6: e1261241, 2016.

16. Pasello G, Zago G, Lunardi F, Urso L, Kern I, Vlacic G, Grosso F, Mencoboni M, Ceresoli GL, Schiavon M, et al: Malignant pleural mesothelioma immune microenvironment and checkpoint expression: Correlation with clinical-pathological features and intratumor heterogeneity over time. Ann Oncol 29: 1258-1265, 2018.

17. Watanabe T, Okuda K, Murase T, Moriyama S, Haneda H, Kawano O, Yokota K, Sakane T, Oda R, Inagaki H and Nakanishi R: Four immunohistochemical assays to measure the PD-L1 expression in malignant pleural mesothelioma. Oncotarget 9: 20769-20780, 2018.

18. Mansfield AS, Roden AC, Peikert T, Sheinin YM, Harrington SM, Krco CJ, Dong H and Kwon EC: B7-H1 expression in malignant pleural mesothelioma is associated with sarcomatoid histology and poor prognosis. J Thorac Oncol 9: 1036-1040, 2014.

19. Cedrés S, Ponce-Aix S, Zugazagoitia J, Sansano I, Enguita A, Navarro-Mendivii A, Martinez-Marti A, Martinez P and Felip E: Analysis of expression of programmed cell death 1 ligand 1 (PD-L1) in malignant pleural mesothelioma (MPM). PLoS One 10: e0121071, 2015.

20. Thapa B, Salcedo A, Lin X, Walkiewicz M, Murone C, Ameratunga M, Asadi K, Deb S, Barnett SA, Knight S, et al: The immune microenvironment, genome-wide copy number aberrations, and survival in mesothelioma. J Thorac Oncol 12: 850-859, 2017.

21. Combaz-Lair C, Galateau-Sallé F, McLeer-Florin A, Le Stang N, David-Boudet L, Duruisseaux M, Ferretti GR, Brambilla E, Lebecque S and Lantuejoul S: Immune biomarkers PD-1/PD-L1 and TLR3 in malignant pleural mesotheliomas. Hum Pathol 52: 9-18, 2016.

22. Burtness B, Harrington KJ, Greil R, Soulières D, Tahara M, De Castro G Jr, Psyrri A, Baste Rotllan N, Neupane PC, Bratland A, et al: KEYNOTE-048: Phase 3 study of first-line pembrolizumab $(\mathrm{P})$ for recurrent/metastatic head and neck squamous cell carcinoma (R/M HNSCC). Presented at ESMO Congress, Munich, 2018.

23. Minnema-Luiting J, Vroman H, Aerts J and Cornelissen R: Heterogeneity in immune cell content in malignant pleural mesothelioma. Int J Mol Sci 19: pii: E1041, 2018.

24. Baretti M and Le DT: DNA mismatch repair in cancer. Pharmacol Ther 189: 45-62, 2018.

25. Dudley JC, Lin MT, Le DT and Eshleman JR: Microsatellite instability as a biomarker for PD-1 blockade. Clin Cancer Res 22: 813-820, 2016.

26. Cohen R, Pellat A, Boussion H, Svrcek M, Lopez-Trabada D, Troudilloud I, Afchain P and André T: Immunotherapy and metastatic colorectal cancers with microsatellite instability or mismatch repair deficiency. Bull Cancer 106: 137-142, 2019.

27. Le DT, Durham JN, Smith KN, Wang H, Bartlett BR, Aulakh LK, Lu S, Kemberling H, Wilt C, Luber BS, et al: Mismatch repair deficiency predicts response of solid tumors to PD-1 blockade. Science 357: 409-413, 2017.

28. Chalmers ZR, Connelly CF, Fabrizio D, Gay L, Ali SM, Ennis R, Schrock A, Campbell B, Shlien A, Chmielecki J, et al: Analysis of 100,000 human cancer genomes reveals the landscape of tumor mutational burden. Genome Med 9: 34, 2017.

29. Ponti G, Losi L, Martorana D, Priola M, BoniE, Pollio A, Neri TM and Seidenari S: Clinico-pathological and biomolecular findings in Italian patients with multiple cutaneous neurofibromas. Hered Cancer Clin Pract 9: 6, 2011.

30. Neuman T, London M, Kania-Almog J, Litvin A, Zohar Y, Fridel L, Sandbank J, Barshak I and Vainer GW: A harmonization study for the use of 22C3 PD-L1 immunohistochemical staining on ventana's platform. J Thorac Oncol 11: 1863-1868, 2016.

31. Herbst RS, Baas P, Kim DW, Felip E, Pérez-Gracia JL, Han JY, Molina J, Kim JH, Arvis CD, Ahn MJ, et al: Pembrolizumab versus docetaxel for previously treated,PD-L1-positive, advanced non-small-cell lung cancer (KEYNOTE-010): A randomised controlled trial. Lancet 387: 1540-1550, 2016 
32. Rusch VW, Chansky K, Nowak AK, Rice D, Kindler H, Gill RR and Travis WD: Malignant pleural mesothelioma. In: Amin B Editor. AJCC Cancer staging Manual. 8th edition. Switzerland, Springer, pp457-468, 2017.

33. Taube JM: Unleashing the immune system: PD-1 and PD-Ls in the pre-treatment tumor microenvironment and correlation with response to PD-1/PD-L1 blockade. Oncoimmunology 3: e963413, 2014.

34. Topalian SL, Sznol M, McDermott DF, Kluger HM, Carvajal RD, Sharfman WH, Brahmer JR, Lawrence DP, Atkins MB, Powderly JD, et al: Survival, durable tumor remission, and long-term safety in patients with advanced melanoma receiving nivolumab. J Clin Oncol 32: 1020-1030, 2014.

35. Garon EB, Rizvi NA, Hui R, Leighl N, Balmanoukian AS, Eder JP, Patnaik A, Aggarwai C, Gubens M, Horn L, et al: Pembrolizumab for the treatment of non-small-cell lung cancer. N Engl J Med 372: 2018-2028, 2015.

36. Borghaei H, Paz-Ares L, Horn L, Spigel DR, Steins M, Ready NE, Chow LQ, Vokes EE, Felip E, Holgado E, et al: Nivolumab versus docetaxel in advanced nonsquamous non-small-cell lung cancer. N Engl J Med 373: 1627-1639, 2015.

37. Brahmer J, Reckamp KL, Baas P, Crinò L, Eberhardt WE, Poddubskaya E, Antonia S, Pluzanski A, Vokes EE, Holgado E, et al: Nivolumab versus docetaxel in advanced squamous-cell non-small-cell lung cancer. N Engl J Med 373: $123-135,2015$.

38. Valmary-Degano S, Colpart P, Villeneuve L, Monnien F, M'Hamndi L, Lang Averous G, Capovilla M, Bibeau F, Laverriere $\mathrm{MH}$, Verriele-Beurrier V, et al: Immunohistochemical evaluation of two antibodies against PD-L1 and prognostic significance of PD-L1 expression in epithelioid peritoneal malignant mesothelioma: A RENAPE study. Eur J Surg Oncol 43: $1915-1923,2017$
39. Hamid $\mathrm{O}$ and Carvajal RD: Anti-programmed death-1 and anti-programmed death-ligand 1 antibodies in cancer therapy. Expert Opin Biol Ther 13: 847-861, 2013.

40. Mittal D, Gubin MM, Schreiber RD and Smyth MJ: New insights into cancer immunoediting and its three component phases-elimination, equilibrium and escape. Curr Opin Immunol 27: 16-25, 2014

41. Al-Shibli KI, Donnem T, Al-Saad S, Persson M, Bremnes RM and Busund LT: Prognostic effect of epithelial and stromal lymphocyte infiltration in non-small cell lung cancer. Clin Cancer Res 14: 5220-5227, 2008.

42. Galon J, Costes A, Sanchez-Cabo F, Kirilovsky A, Mlecnik B, Lagorce-Pagès C, Tosolini M, Camus M, Berger A, Wind P, et al: Type, density, and location of immune cells within human colorectal tumors predict clinical outcome. Science 313: 1960-1964, 2006.

43. Mahmoud SM, Paish EC, Powe DG, Macmillan RD, Grainge MJ, Lee AH, Ellis IO and Green AR: Tumor-infiltrating CD8+ lymphocytes predict clinical outcome in breast cancer. J Clin Oncol 29: 1949-1955, 2011

44. Yamada N, Oizumi S, Kikuchi E, Shinagawa N Konishi-Sakakibara J,Ishimine A, Aoe K, Gemba K, Kishimoto T, Torigoe $\mathrm{T}$ and Nishimura M: CD8+ tumor-infiltrating lymphocytes predict favorable prognosis in malignant pleural mesothelioma after resection. Cancer Immunol Immunother 59: 1543-1549, 2010.

45. Burt BM, Rodig SJ, Tilleman TR, Elbardissi AW, Bueno R and Sugarbaker DJ: Circulating and tumor-infiltrating myeloid cells predict survival in human pleural mesothelioma. Cancer 117: 5234-5244, 2011

46. Arulananda S, Thapa B, Walkiewicz M, Zapparoli GV, Williams DS, Dobrovic A and John T: Mismatch repair protein defects and microsatellite instability in malignant pleural mesothelioma. J Thorac Oncol 13: 1588-1594, 2018. 